\title{
Nutritional Intake of Fetus in Pregnancy in Medical and Koran Perspective: A Literature Review
}

\author{
Tamrin Talebe ${ }^{1}$, Haerani Harun ${ }^{2}$, M Sabir $^{3}$ \\ \{tamrintalebe@gmail.com ${ }^{1}$, haeraniharun.unhas@gmail.com², msabiruntad16@gmail.com ${ }^{3}$ \} \\ Faculty of Ushuluddin, Islamic Institute of Datokarama, Palu Indonesia ${ }^{1}$, Student of Doctoral \\ Program, Faculty of Public HealthHasanuddin University, Makassar, Indonesia ${ }^{2}$, Medical \\ Faculty, Tadulako University, Palu, Indonesia ${ }^{3}$
}

\begin{abstract}
The maternal mortality rate in Indonesia is quite high. Nutritional factors play a role in physiological processes during pregnancy such as anemia and decreased immunity. Nutritional intake is very important in pregnancy. Various nutritional demand in pregnancy play important role in fetus growth and health. In medical field, nutritional status of a pregnant woman has a lot of concern and has been studied due to the survive of the mother and the fetus. The Koran's call to fulfill the needs during pregnancy is expressed through the command to consume good food. The Koran provide guidence including in the fetus and mother care. This is a literature review,various references were collected from books and online database including reports and journals. The articles were screened according to the research objectives. The keywords used are pregnancy nutrition, fetus gowth and Koran view of pregnancy.
\end{abstract}

Keyword: nutritional, pregnancy, fetus, Koran

\section{Introduction}

Pregnant women have physiological changes during pregnancy to fulfill the needs of homeostasis and fetal growth. These physiological changes are achieved by adjusting the maternal organ systems. These changes aim to meet the needs of the fetus without harming the maternal body. Throughout the pregnancy, the fetus depends on the nutritional intake from the mother [1].

Imbalance maternal nutritional intake can endanger the mother and the baby and can increase the maternal mortality rate. The maternal mortality rate in Indonesia is quite high. Nutritional factors play a role in pathological processes during pregnancy such as anemia and decreased immunity. Anemia in pregnant women can be caused by iron (Fe) deficiency. Inadequate nutritional intake during pregnancy can also cause a decrease in maternal immunity [1].

The Koran mentions the stages of growth and development of the fetus in the mother's womb as an inseparable relationship such as nuthfah, 'alaqah, mudgah, kasaunal izam. The importance of fulfilling nutrition, especially the nutrition of a mother for her baby in a series of expressions for the stages of fetal growth, expressed in the form of general sentence boundaries, in the form of orders for consuming halal and thayyib foods, limiting excessive food consumption and certain types of prohibited foods to ethical aspects of consuming them. 


\section{Methods}

This is a literature reviewarious references were collected from books and online database including articles and journals. The articles and journals were screened according to the research objectives. The keywords used are pregnancy nutrition, fetus growth, Koran view of nutrition and Koran view of pregnancy.

\section{Result and Discussion}

\subsection{Nutritional needs in Pregnancy}

Nutritional intake is very important in pregnancy. Mothers with malnutrition are more likely to give birth to low birth weight babies (LBW) than mothers with good nutrition. Fetal nutritional intake during pregnancy determines fetal growth and development and has a major impact on fetal life after birth.[1]

The fetus receives iron transfer from the mother starting at week 30. Serum transferrin carries substances from the mother's blood circulation to the transferrin receptors on the syncytiotrophoblast placenta, holotransferrin is endocytosis, iron is released and apothransferrin is returned to the maternal blood circulation. This system of iron transfer through the placenta regulates iron transport from mother to fetus. When the mother is iron deficient, the number of transferrin receptors in the placenta increases so that iron absorption becomes more [2]. The need for dietary iron increases in pregnancy due to the increased mass of red blood cells to accommodate the fetus and the development of the placenta and for the preparation for excessive blood loss during childbirth [3].

Some studies show that vitamin D status during pregnancy affects fetal bone development. Children aged 9 years with vitamin D deficiency mothers during pregnancy have smaller bone size and decreased bone mineral content. Adequate vitamin D intake during pregnancy is needed for optimal bone development in children [4].

Zinc is essential for fetal growth and development. Zinc deficiency can affect fetal development by reducing cell proliferation, reducing protein synthesis or decreasing the polymerization rate of tubulin. Animal studies have shown that zinc deficiency is teratogenicity, which can interfere with normal fetal development [3].

Calcium requirements also increase during pregnancy. Calcium is needed in various fetal development functions and is very important in fetal bone development. Calcium absorption and excretion in urine are doubled from pre-conception and postpartum.

Folic acid requirement increases during pregnancy because of the fetus growth demand. It has been known that folic acid at conception helps reduce the risk of neural tube defects. Calcium requirements also increase during pregnancy. Calcium is essential in various fetal development functions and is very important in fetal bone development. Calcium absorption and excretion in urine are doubled from pre-conception and postpartum. Fatty acids are essential nutrients for growth in the uterus. Decosahexanoic acid (DHA) has an important role in fetal growth and fetal nervous system among long chain omega-3 polyunsaturated fatty acids [3]. 


\subsection{Nutritional changes in Pregnancy}

Nutrition in pregnancy supplies energy needs for both mother and fetus. Two things that are emphasized during pregnancy related to nutritional intake are weight gain and various nutritional needs. During pregnancy there is an increase in basal metabolism by $15-20 \%$. Metabolic changes are influenced by hormonal factors which aim to create an environment that supports fetal growth [1].

The early half of pregnancy is a preparation for fetal growth at last half of the pregnancy. Corpus luteum and placenta secreted hormones that play a role in maintaining pregnancy and also affect metabolism during pregnancy. Estrogen is a hormone synthesized in a complex way that involves the mother, fetus and placenta. This hormone effect the uterus and other reproductive organs. Estrogen also influences carbohydrate, fat and bone metabolism.[5]

Fetal nutritional requirements generally increase at the last half of gestation when $>90 \%$ fetal growth occurs, changes in pregnancy nutrition metabolism begin in the first week. The rapid growth of the fetus during the last half of pregnancy causes changes in basal metabolism, protein and minerals. About $60 \%$ of the increase in basal metabolic rate occurs in the last half of gestation when the metabolic requirements of fetal tissue synthesis are greatest. Maternal fat stores are generally collected between the 10th and 30th weeks of pregnancy before fetal energy requirements reach its peak. About $3.3 \mathrm{~kg}$ of fat is used as a reserve, providing energy needs of approximately $30,000 \mathrm{kcal}, 0.5 \mathrm{~kg}$ of fat stored in the fetus [5].

Shift in protein metabolism are complex and change gradually during pregnancy so that nitrogen requirements for fetal growth reach their full potential at the end of pregnancy. The reduction in total nitrogen excretion during late gestation indicates that amino acids are used for tissue synthesis. The total decrease in amino acids is around $15-25 \%$ which reflects the increased consumption of the placenta. Maternal oxidation of amino acids for energy decreases at the end of pregnancy, increasing the amount of energy available for transfer to the fetus. There is no evidence that pregnant women store protein early in pregnancy for later fetal use. The increased demand at the end of pregnancy must match the physiological adjustments that require protein. When the supply of food decreases, there are physiological changes needed to meet the needs of the fetus [5].

The requirement of the fetus during pregnancy doubled the nutritional requirements. Accumulated energy needed to increase the basal metabolic rate during pregnancy to protect the fetus is about $36,000 \mathrm{kcal}$; the daily energy requirement in the final quarter of pregnancy is 230 kcal. To meet these energy needs, several of these changes can be found: 1) a decrease in the rate of lipid synthesis and storage of maternal fat reserves, 2) a change in the intensity of physical activity and 3) an increase in food consumption so that energy intake increases [5].

\subsection{Efforts to fulfill nutritional needs in pregnancy}


Increasing iron levels only from food is difficult, especially in women who enter pregnancy with less iron intake. This increases the likelihood that the baby will be born prematurely or LBW.[3] Iron supplementation is an effort to reduce the risk of iron deficiency during pregnancy. However, there is still some doubt about the benefits of iron during pregnancy. Iron supplementation has been shown to increase hemoglobin, serum ferritin and serum Fe levels. These iron improvements are seen in the final trimester even in women entering pregnancy with good iron levels. This supplementation helps reduce the acceleration of iron depletion in the final trimester of pregnancy. However, in women who enter pregnancy with deficiency of iron reserves, iron supplementation sometimes fails to prevent iron deficiency anemia [2].

The benefits of iron supplements are seen increasing after childbirth. Data suggest that iron supplementation during pregnancy helps increase maternal hemoglobin levels for up to 2 months after delivery and increases iron stores for up to 6 months after delivery. Increased iron stores are especially beneficial for women who get pregnant again in a relatively short time after giving birth. The mother enters a pregnancy with a good iron status and reduces the risk of iron deficiency and anemia in subsequent pregnancies and some women who give birth experience anemia due to blood loss [2]. Maternal folic acid status is largely determined by folic acid supplementation and other factors such as intake of folic acid from food and genetic variation. This supplementation is important to prevent neural tube defects in the newborn [3].

\subsection{Koran and fetal growth}

The fetus in the womb will have a good growth if it is supported by good support around it, including is good nutrition for pregnant women. The Koran reveals the stages of normal fetal growth and development through structured of stages. In surah al-mukminun verses 12-14:Then We made the sperm-drop into a clinging clot, and We made the clot into a lump (of flesh), and We made (from) the lump, bones, and We covered the bones with flesh; then We developed him into another creation. So blessed is Allah, the best of creators. The fatus goes through phases include: Nuthfah as the initial start of fetal growth which means pearls or clear water [6]. This process will be absent without amsyaj process. The process of mixing sperm cells with eggs during sexual intercourse.[7]The process of 'alaqah described in the Koran as an advanced stage of the nuthfah process after conception. 'Alaqah literally means sticking, clinging or hanging. The results of fertilization of sperm and ovum cells in the uterus from the formation of nuthfah and dividing themselves into two, four and so on. The fertilized cells will continue to get to the uterine wall and put is self in the uterine wall [6]. These process will naturally continue in a good and healthy environment as part of the human creation.

The fetus growth phase is very much determined by the nutritional intake it receives from the mother. As mentioned at the beginning of the process of growing with nutfah and switching to the process of 'alaqah, The process by which a sperm cell is produced and flows through the ribs between the backbone of the man and meets the egg cell of a woman, then changes into a long, red 'alaqah lump.[8]The Koran describes the growth and development of the fetus in the womb with the words Qarar Makin. Qarar, based on the language means that he remains silent in his place in a safe position, such as the dwelling place of a human being on earth because it has conformity in 
fulfilling the necessities of life. Therefore, the meaning desired in each lafadz alaqah and mudhgah in the Koran also has an indication of the relationship between the behavior of pregnant women and the involvement of the head of the family and other family members in fulfilling the nutrition of pregnant women.

\subsection{Nutritional Fulfillment Of Pregnant Woman And The Fetus In Tha Koran}

Physical health and fulfillment of nutrition from a mother for her pregnancy will affect the stability of the growth of a healthy fetus. Every stage of change that occurs between a mother and her fetus is an inseparable part that even supports each other's life order [9]. The Koran's call to fulfill the needs during pregnancy is expressed through the command to consume good food (thayyib) meaning that this good activity will also affect one's biological physical quality. In Surah al-Baqarah verse 168: O mankind, eat from whatever is on earth (that is) lawful and good and do not follow the footsteps of Satan.It is stated that humans are given the widest freedom possible to make efforts to process food staples to support their survival. Food can be sourced from grains, vegetable plants and animals, not from forbidden, either prohibited from obtaining it such as violence and coercion or forbidden because of its kind, such as khamr [10].

Halalan accompanied by the sentence Tayyiban means that food that is allowed to be consumed is food that is useful for the body, does not have a destructive or other negative effect either on oneself or on others. Food consumption must be in accordance with God's instructions.

The fetus's ability to learn will grow based on the activities of pregnant women. The behavior carried out by pregnant women will have a direct impact on fetal behavior to behave. The ability to orient and link the external world in the fetus is also influenced by the nutritional stimuli it feeds. The treatment of pregnant women in serving the nutritional needs of their fetuses appropriately will have a positive impact both physically and psychologically. Naturally, the relationship between pregnant women and their fetuses in providing nutrition is connected through the umbilical cord. If the nutritional nutrition provided is balanced, the fetus will have a strong basis for growth and development.[11]It can be said that consuming halal and nutritious food is Allah's command to all mankind. In fact, the attitude of fulfilling halal nutrition is the same as protecting oneself from bad behavior.

The fetus that is conceived by a pregnant woman is part of a creature created by God and has the right to receive her rights, including nutritional intake. The availability of this source of nutritional intake has been prepared by God in the QS al-an'am verse99: And it is He who sends down rain from the sky, and We produce thereby the growth of all things. We produce from it greenery from which We produce grains arranged in layers. And from the palm trees - of its emerging fruit are clusters hanging low. And (We produce) gardens of grapevines and olives and pomegranates, similar yet varied. Look at (each of) its fruit when it yields and (at) its ripening. Indeed in that are signs for a people who believe. Allah SWT teaches in this verse various kinds of knowledge about daily food that are a human need if they want to improve the quality of their physical and psychological endurance. Pregnant women and fetuses really need macro and micro nutrients such as carbohydrates, protein, fat, vitamins, minerals and so on. The disclosure of 
various food sources is sufficient to indicate that the quality of its nutritional content is very beneficial for humans, especially for pregnant women and the fetus, such as the mention of "green plants" which are needed by fetuses and pregnant women.[6]Beside the green plants, vitamin needs are also provided in the various fruits that green plants produce. In the verse it is mentioned: We produce from it greenery from which We produce grains arranged in layers. The green fruit is rich in various nutrients and health benefits, according to the typology of the growing region [12].

Likewise, Allah SWT mentions fruits with various benefits for human health. And from the palm trees - of its emerging fruit are clusters hanging low. And (We produce) gardens of grapevines and olives and pomegranates, similar yet varied. Look at (each of) its fruit when it yields and (at) its ripening. The variety of fruit mentioned indicates a variety of nutritional content in each fruit. The mention of dates as fruits of the Arabian desert valley, grapes, olives and other fruits that have similar nutritional content are very useful, especially in the fulfillment of folic acid, omega-3, fiber, magnesium, iron, phosphorus, calcium, beta-carotene, vitamin A, vitamin B1 , vitamin $\mathrm{C}$ and other types of nutrients essential for health even for pregnancy. The same thing is also described in surah annahl verse 11: He causes to grow for you thereby the crops, olives, palm trees, grapevines, and from all the fruits. Indeed in that is a sign for a people who give thought. Scientists are given the freedom of mind to do experiments on various types of fruits and plants that are beneficial for human.[6]

Pregnant women and the fetus also need calcium, protein, iron and vitamin D for the health and development of their fetuses. The nutritional content of milk and consuming it according to the level of need will meet their intake needs. And indeed, for you in grazing livestock is a lesson. We give you drink from what is in their bellies - between excretion and blood - pure milk, palatable to drinkers. In this verse (Surah Annahl; 66) the sentence emphasizes and reinforces the meaning it contains, in the body of animals such as goats, cows or camels, there are many foodstuffs needed by humans, including pregnant women and their fetuses. Red meat is a basic necessity for pregnant women who experience iron deficiency which causes anemia and results in the birth of premature children with low body weight. Milk provided by the animal also has very beneficial properties for humans that cannot be ignored.

The nutritional content in fish meat has enormous benefits for a pregnant woman and the growth of her fetus. The fetus has a need to develop completely which can only be met through the intake of a pregnant mother. Physical brain growth and psychological intelligence are very much determined by the omega 3 fatty acids, vitamin B2, calcium, phosphorus and minerals given. The Koran mentions fish as a special food in the Koran surah Annahl; 14: And it is He who subjected the sea for you to eat from it tender meat and to extract from it ornaments which you wear. In this verse, it is mentioned the various nutrition that humans can taste freely. Humans can get this taste of a fish to meet their daily needs. The balance of nutrients in the animal is needed for human food source which is sunnatullah. God has arranged this resource from nature for humans the ease of obtaining it [6].

Nutritional needs of pregnant women is important to maintain the health and growth of the fetus. But overfilling is also dangerous. Consumption of multivitamins in addition to fruit intake will actually be toxic and damage the body's organs and even become congenital defects for the fetus. The Koran has reminded us to fulfill nutritional intake in orders and need to be aware of prohibitions so that they must be avoided. Meeting the nutritional needs of pregnant women is a must to maintain the health and development of the fetus. But overfilling is also very dangerous. 
Consumption of multivitamins in addition to fruit intake will actually be toxic and damage the body's organs and even become congenital defects for the fetus. The Koran has reminded us to fulfill nutritional intake in the form of orders and to be aware of prohibitions so that they must be avoided.

In The Koran surah al-A'raf verse 31 stated: ... and eat and drink, but be not excessive. Indeed, He likes not those who commit excess. Food consumption model for someone is consumption that is halal and good and not excessive. As long as fodd is consumed in a balanced manner according to the needs, the condition of pregnant women and the fetus, not only pregnant women will feel happiness from their pregnancy activities, but the baby born will grow and develop healthily. In the pre-Islamic period, when the pilgrimage season had come, the people jahiliyah preferred to consume high carbohydrate intake and not consume good and healthy foods that added vitamins and balanced nutrition. Praying activities are also very much needed by consuming healthy and regular foods and avoiding physical problems caused by excessive consumption. Excessive consumption can be interpreted as excessive in portions that can cause in disease, excessive storing so that a lot of food is wasted due to expiration and excessive prohibition because it promotes the desire for consumption of haram foods.[6]

\section{Conclusion}

Nutritional intake is very important in pregnancy. Lack of maternal malnutrition increased the risk to give birth to LBW babies. Fetal nutritional intake during pregnancy determines fetal growth and development and has a major impact on fetal life after birth. Some nutritional needs beside major nutrition include iron, zinc, folic acid, calcium, vitamin $\mathrm{D}$ and etc. This nutrition can be obtained from food and supplement to fulfill the mother and the fetus demands. The Koran order not only to fulfill the needs the of the mother and fetus by nutritious and healthy foods but also consume halalan and thayyiban food.

\section{Reference}

[1] S. Setiati and P. W. Laksmi, Peran Internis dalam tata laksana penyakit-penyakit pada kehamilan. PIPInterma, 2019.

[2] L. H. Allen, "Anemia and iron deficiency: effects on pregnancy outcome," Am. J. Clin. Nutr., vol. 71, no. 5, pp. 1280S-1284S, May 2000, doi: 10.1093/ajen/71.5.1280s.

[3] J. A. Grieger and V. L. Clifton, "A Review of the Impact of Dietary Intakes in Human Pregnancy on Infant Birthweight," Nutrients, vol. 7, no. 1, pp. 153-178, Jan. 2015, doi: 10.3390/nu7010153.

[4] C. R. Gale et al., "Maternal vitamin D status during pregnancy and child outcomes," Eur. J. Clin. Nutr., vol. 62, no. 1, pp. 68-77, Jan. 2008, doi: 10.1038/sj.ejen.1602680.

[5] J. C. King, "Physiology of pregnancy and nutrient metabolism," Am. J. Clin. Nutr., vol. 71, no. 5, pp. 1218S-1225S, May 2000, doi: 10.1093/ajen/71.5.1218s.

[6] A. S. Muhammad, Alquran dan Tafsirnya, vol. 6. Indonesia: Departemen Agama RI, 2009.

[7] A. H. Faris, Mu'jam al-Maqayis fi al-Lughah, vol. 1. Mesir: Dar al-Fikr, 1994. 
[8] A. ALu Syaikh, Lubab al-Tafsir min Ibni Katsir, vol. 6. Kairo: Muassasah Dar al-Hilal, 1994.

[9] H. Yahya, The Miracle of Creation of the Human Being, vol. 1. Jakarta: Global Media, 2003.

[10] A. B. N. as-Sa'di, Tafsir Karimirahman fi Tafsir Kalamil Mannan, vol. 1. Makkah: Darul Haq, 2004.

[11] M. Hanafi, Tafsir Alquran Tematik, 2nd ed. Jakarta: Akubisa, 2012.

[12] W. al-Zuaili, Tafsir al-Munir, vol. 7. Mesir, 2014. 